\title{
Clinical impact of a commercially available multiplex PCR system for rapid detection of pathogens in patients with presumed sepsis Christine Dierkes*1, Boris Ehrenstein ${ }^{1}$, Sylvia Siebig1, Hans-Jörg Linde², Udo Reischl ${ }^{2}$ and Bernd Salzberger ${ }^{1}$
}

\author{
Address: ${ }^{1}$ Department of Internal Medicine I, University Hospital Regensburg, 93042 Regensburg, Germany and ${ }^{2}$ Institute of Medical \\ Microbiology and Hygiene, University of Regensburg, 93042 Regensburg, Germany \\ Email: Christine Dierkes* - Christine.dierkes@klinik.uni-r.de; Boris Ehrenstein - boris.ehrenstein@klinik.uni-regensburg.de; \\ Sylvia Siebig - sylvia.siebig@klinik.uni-r.de; Hans-Jörg Linde - hans-joerg.linde@klinik.uni-r.de; Udo Reischl - udo.reischl@klinik.uni-r.de; \\ Bernd Salzberger - bernd.salzberger@klinik.uni-regensburg.de \\ * Corresponding author
}

Published: II August 2009

BMC Infectious Diseases 2009, 9:126 doi:10.1186/147/-2334-9-126

This article is available from: http://www.biomedcentral.com//47/-2334/9//26

(c) 2009 Dierkes et al; licensee BioMed Central Ltd.

This is an Open Access article distributed under the terms of the Creative Commons Attribution License (http://creativecommons.org/licenses/by/2.0), which permits unrestricted use, distribution, and reproduction in any medium, provided the original work is properly cited.

\begin{abstract}
Background: Timely identification of pathogens is crucial to minimize mortality in patients with severe infections. Detection of bacterial and fungal pathogens in blood by nucleic acid amplification promises to yield results faster than blood cultures (BC). We analyzed the clinical impact of a commercially available multiplex PCR system in patients with suspected sepsis.

Methods: Blood samples from patients with presumed sepsis were cultured with the Bactec $9240^{\mathrm{TM}}$ system (Becton Dickinson, Heidelberg, Germany) and aliquots subjected to analysis with the LightCycler ${ }^{\circledR}$ SeptiFast ${ }^{\circledR}$ (SF) Test (Roche Diagnostics, Mannheim, Germany) at a tertiary care centre. For samples with PCR-detected pathogens, the actual impact on clinical management was determined by chart review. Furthermore a comparison between the time to a positive blood culture result and the SF result, based on a fictive assumption that it was done either on a once or twice daily basis, was made.
\end{abstract}

Results: Of I0I blood samples from 77 patients, 63 (62\%) yielded concordant negative results, 14 (13\%) concordant positive and $9(9 \%)$ were BC positive only. In 14 (13\%) samples pathogens were detected by SF only, resulting in adjustment of antibiotic therapy in 5 patients (7,7\% of patients). In 3 samples a treatment adjustment would have been made earlier resulting in a total of 8 adjustments in all $10 \mathrm{I}$ samples (8\%).

Conclusion: The addition of multiplex PCR to conventional blood cultures had a relevant impact on clinical management for a subset of patients with presumed sepsis.

\section{Background}

Early adequate antibiotic treatment improves the outcome of patients with sepsis [1-5]. Even if broad spectrum antibiotics are used empirically, adjustments of antimi- crobial therapy may be necessary. Generally adjustments are based on the results of positive blood or other cultures that are available after 8 to 48 hours [6]. 
Additionally, the likelihood of a positive result in conventional culture methods can be reduced by concomitant or prior antibiotic treatment. Amplification of bacterial and fungal nuclear acids directly from blood specimen is a newly established detection method for pathogens. Tests based on this method may improve clinical care by shortening the time to a positive result and by being more independent of antibiotic pre-treatment. The impact of these methods on therapeutic decisions and outcome has not yet been studied.

We compared the results of a standard BC system with those of a commercially available polymerase chain reaction (PCR) based system in routine clinical management.

Primary goal of the study was to determine if results from the additional PCR based system led to different therapeutic decisions than the results from $\mathrm{BC}$ alone.

Secondary goal was to assess the concordance of both methods and time saving effects with the use of a PCRbased test.

\section{Methods}

A commercially available molecular based test system (LightCycler $^{\circledast}$ SeptiFast ${ }^{\circledR}$ (SF) Test; Roche Diagnostics, Mannheim, Germany) was offered as an add-on diagnostic tool free of charge supplemental to standard BCs taken in patients with presumed sepsis at the Regensburg university medical centre during an eight months period (July 2006 - March 2007). The test was made available to all departments treating patients with sepsis by the microbiology department. The decision to use the additional test was solely made by the treating clinician.

The SeptiFast ${ }^{\circledR}$ Test is able to detect 25 different pathogens directly from blood by real-time multiplex PCR (Table 1) [7]. The limits of detection were $100 \mathrm{CFU} / \mathrm{ml}$ for coagulase-negative staphylococci, C. glabrata and Streptococcus spp. and $30 \mathrm{CFU} / \mathrm{ml}$ for all other pathogens listed in the table [8].
Both the sample for the $\mathrm{BC}$ and the sample for the SF were taken through the same blood drawing device. Both aerobic and anaerobic BC bottles (Bactec 9240 BC system, Becton Dickinson, Heidelberg, Germany) were inoculated directly with $10 \mathrm{ml}$ blood each and delivered to the microbiology department together with the aliquot for analysis with the SF. Blood cultures were incubated for 7 days. The SF-test was provided free of charge by the manufacturer.

A retrospective analysis of the test results and clinical data was performed. Clinical data were extracted by chart review (underlying illness, antibiotic pre-treatment, epidemiological data such as age, sex, length of stay, hospital mortality, immunosuppression, SIRS criteria (Temperature $\leq 36^{\circ} \mathrm{C}$ or $\geq 38^{\circ} \mathrm{C}$, heart rate $\geq 90 \mathrm{bpm}$, respiratory rate $\geq 20$ breaths $/ \mathrm{min}$ or $\mathrm{paCO}_{2}<32 \mathrm{mmHg}$, white blood cell count $\geq 12,000$ or $\leq 4,000$ cells $/ \mathrm{mm}^{3}$ )) and by the data provided for the test application. Immunosuppression was defined as being post organ-transplant, receiving chemotherapy for malignant disease or receiving high dose prednisolone ( $>20 \mathrm{mg} /$ day). Those with chronic disease predisposing for infections such as chronic liver disease or alcoholism were not counted as such. Antibiotic pre-treatment was defined as having received any antibiotic therapy within 24 hours before specimen collection. Multiple samples per patient were allowed, if the times of blood collection were at least 48 hours apart.

To determine the impact of the results on the patients' therapy, data were independently reviewed by two infectious disease specialists. They analyzed the current antibiotic therapy and possible adaptations necessary for optimal treatment according to current standard of care. In case of both SF and $\mathrm{BC}$ yielding positive results, the possible time saving effect of the SF-test was determined.

Treatment adjustments were classified into two different categories: 1) Treatment adjustment not necessary (either due to coverage by the empirical therapy or to lacking clinical relevance); 2) Treatment adjustment necessary due to lacking coverage of empirical therapy.

Table I: SeptiFast ${ }^{\circledR}$ Portfolio: Pathogens detected by SeptiFast ${ }^{\circledR}$.

\begin{tabular}{|c|c|c|}
\hline Gram-negative bacteria & Gram-positive bacteria & Fungal pathogens \\
\hline Escherichia coli & Staphylococcus aureus & Candida albicans \\
\hline Klebsiella pneumoniae & Coagulase-negative & Candida tropicalis \\
\hline Klebsiella oxytoca & Staphylococci & Candida parapsilosis \\
\hline Serratia marcescens & Streptococcus pneumoniae & Candida krusei \\
\hline Enterobacter cloacae & Streptococcus spp. & Candida glabrata \\
\hline Enterobacter aerogenes & Enterococcus faecium & Aspergillus fumigatus \\
\hline Proteus mirabilis & Enterococcus faecalis & \\
\hline \multicolumn{3}{|l|}{ Pseudomonas aeruginosa } \\
\hline \multicolumn{3}{|l|}{ Acinetobacter baumannii } \\
\hline \multicolumn{3}{|l|}{ Stenotrophomonas } \\
\hline maltophilia & & \\
\hline
\end{tabular}


In order to examine possible time saving effects of the molecular based analysis, time to results of BCs was compared to the time of SF results. At our institution $\mathrm{BC}$ results are reported to the treating physician by telephone call from 8 am to 7 pm Monday-Friday and 9 am -4 pm on weekends and holidays. A complete report including antibiotic resistance testing results is faxed and sent by mail. Due to the experimental status of the SF-test, the results were not available on a daily basis. Therefore a virtual once and twice daily analysis Monday-Friday was assumed in order to achieve comparable time frames. For the once daily simulation results were assumed to be available by $2 \mathrm{pm}$ if received by 8 am in concordance with the turnaround times reported for the test. In the twice daily setting results were assumed to be available by $2 \mathrm{pm}$ if SF samples were received by 8 am, if received by $1 \mathrm{pm}$ results were assumed to be available at $7 \mathrm{pm}$. We then compared the time from drawing the blood samples to the time a first positive $\mathrm{BC}$ result was reported and the virtual SF result time.

Data collection and statistical analysis were performed using Microsoft Office Access ${ }^{\circledR}$ (Version 2007, Microsoft Corporation, Redmond, USA) and SPSS ${ }^{\circledast}$ (SPSS Inc, Version 15, Germany).
Due to the retrospective and non-interventional design of the analysis approval of the local ethics committee was not required according to the guidelines of our hospital.

\section{Results}

\section{Patient population}

In the study period 101 samples of 77 patients were examined. The median age of the patients was 55 years (Table 2 ). In-Hospital mortality was $33 \%$ with a median length of stay of 35 days. Eighty-three patients (82\%) were treated in the ICU while the blood samples were taken. Two or more SIRS criteria were present in 79 patients at the time of specimen collection (78\%), one positive SIRS criteria in 13 patients, no SIRS criteria in 8 patients (missing data in one patient). Thirty-five of the patients (45\%) were immunocompromised. In 40 patients from surgical and 37 from medical wards a broad spectrum of diseases and comorbidities was present. Concomitant antibiotic therapy at the time of specimen collection had been administered in 61 patients with 83 samples (81\%) studied.

\section{Isolated Pathogens}

In 39 samples (38\%) pathogens were identified from either BC or SF (Table 3). Both methods yielded predom-

Table 2: Patient characteristics: Patient characteristics stratified by SeptiFast ${ }^{\circledR}$ (SF) results.

\begin{tabular}{|c|c|c|c|c|c|}
\hline & \multicolumn{3}{|c|}{ SF positive } & \multicolumn{2}{|c|}{ SF negative } \\
\hline & $\begin{array}{l}\text { SF and BC detected } \\
\text { same pathogen }\end{array}$ & $\begin{array}{l}\text { Only SF detected } \\
\text { pathogen }\end{array}$ & $\begin{array}{l}\text { SF and } B C \text { detected } \\
\text { different pathogens }\end{array}$ & BC detected pathogen & $B C$ and SF neg. \\
\hline Number of samples & 14 & 12 & 3 & 9 & 63 \\
\hline Number of patients & 12 & 8 & 2 & 7 & 48 \\
\hline $\begin{array}{l}\text { Patients in ICU at } \\
\text { time of specimen } \\
\text { collection }\end{array}$ & 11 & 11 & 2 & 9 & 50 \\
\hline $\begin{array}{l}\text { Number of samples } \\
\text { drawn with } \\
\text { concomitant } \\
\text { antimicrobial therapy }\end{array}$ & 13 & 12 & 2 & 7 & 50 \\
\hline $\begin{array}{l}\text { Median Age } \\
( \pm \text { SD) [years] }\end{array}$ & $59( \pm 18)$ & & & $52( \pm 17)$ & \\
\hline Gender & 8 female/ 44 male & & & 20 female/35 male & \\
\hline $\begin{array}{l}\text { Median Duration of } \\
\text { hospitalisation }( \pm \text { SD) } \\
\text { [days] }\end{array}$ & $40( \pm 39)$ & & & $34( \pm 43)$ & \\
\hline Hospital mortality & $36.4 \%$ & & & $30.9 \%$ & \\
\hline $\begin{array}{l}\text { Median Number of } \\
\text { SIRS criteria }( \pm \text { SD) }\end{array}$ & $2.9( \pm 1.1)$ & & & $2.2( \pm 1.1)$ & \\
\hline
\end{tabular}

$B C=$ blood culture 
inantly gram-positive bacteria. More pathogens were found in the SF group of patients, mainly due to a higher rate of fungal pathogens and a higher rate of Enterococcus faecium, while the number of coagulase-negative Staphylococci (CNS) was lower with SF. All differences were not statistically significant $(\mathrm{p}>0.05)$.

\section{Concordance of BC and SF}

Fourteen of 101 samples (13\%) were concordant positive in SF and BC systems. Sixty-three (62\%) were negative in both methods. Thus a concordant result was seen in $77 \%$ of all samples. In 13 samples with a negative $\mathrm{BC}$, pathogens were identified by SF (Table 4 ). In additional microbiological samples from the same patient, the identical pathogen was isolated in 9 of those cases (bronchial lavage (3), wound swab (2), tracheal aspirate (1), urine (1), ascites (1), gall fluid aspirate (1)); Table 5.

Fungal pathogens were detected more frequently with the SF-test when present in other clinical isolates (3 Candida species). Enterococcus faecium infection was more often diagnosed in the SF $(n=7)$ test compared to BC $(n=3)$, although neither difference was statistically significant.

In 9 samples with positive $\mathrm{BC}$ the SF-test yielded negative results (Table 6). Listeria monozytogenes isolated from a BC was not detected by the SF-test due to the limited portfolio of the SF-test. Another failure was attributed to technical problems during the analysis. Three times CNS were isolated by $\mathrm{BC}$ while SF did not give a positive result. Four further samples with positive $\mathrm{BC}$ results had no positive result in the SF analysis. Three of those were polymicrobial bloodstream infections with two samples with Entero-

Table 3: Isolated Pathogens: Pathogens identified in BC or SF; 7 samples yielded polymicrobial results.

\begin{tabular}{|c|c|c|}
\hline Species & SeptiFast $^{\circledR}$ & Blood culture \\
\hline Coagulase-negative staphylococci & 3 & 6 \\
\hline Staphylococcus aureus & 5 & 3 \\
\hline Enterococcus faecalis & 2 & 3 \\
\hline Enterococcus faecium & 7 & 3 \\
\hline Klebsiella pneumonia & 2 & I \\
\hline Serratia marcescens & 2 & 2 \\
\hline Escherichia coli & 3 & 2 \\
\hline Enterobacter cloacae/aerogenes & 2 & I \\
\hline Proteus mirabilis & 1 & l \\
\hline Streptococcus species & I & \\
\hline Candida albicans & 2 & 3 \\
\hline Candida glabrata & 1 & \\
\hline Aspergillus fumigatus & 1 & \\
\hline Candida tropicalis & I & I \\
\hline Candida krusei & I & \\
\hline Streptococcus pneumoniae & & l \\
\hline Listeria monozytogenes & & 1 \\
\hline Total & 34 & 28 \\
\hline
\end{tabular}

Table 4: Overall results: Results of blood culture $(B C)$ and SeptiFast ${ }^{\circledR}$ (SF)

\begin{tabular}{lccc}
\hline & BC positive & BC negative & Total SF \\
\hline SF positive & 14 & 13 & 27 \\
SF negative & $9 *$ & 63 & $\mathbf{7 3}$ \\
Total BC & 23 & 77 & $100^{\#}$ \\
\hline
\end{tabular}

* Two samples yielded two different pathogens by $\mathrm{BC}$ but just one by $\mathrm{SF}$

\# One sample yielding different species comparing SF with BC not included in table.

coccus faecalis that failed detection and one Streptococcus pneumoniae bacteraemia. Retrospective analyses of the original data of the LightCycler ${ }^{\circledast}$ system revealed the detection of Streptococcus pneumoniae that had been missed due to a faulty software (V1.1.7., detected in review with revised software, V1.2.1).

The median time to obtain the result of the SF analysis was determined to be 18 hours, with a minimum of 6.75 hours and a maximum of $74 \mathrm{~h}$ (samples collected at the beginning of the weekend) in the twice daily situation, with a median time of 26,25 hours, a minimum of 6,75 hours and a maximum of 79 hours assuming a once daily analysis.

\section{Treatment adjustments}

In samples with both $\mathrm{BC}$ and SF positive a change in therapy would not have been necessary in 11 of the 14 cases (Table 7). For one of those samples the $\mathrm{BC}$ results had been available before completion of the actual SF analysis and a change in therapy had already been executed.

Three samples of 3 different patients could be identified where a treatment adjustment was deemed necessary. In one case an antifungal drug was not included in the empiric regimen; in two other cases vancomycin was necessary additionally. The median time from specimen collection to the SF result was 27 hours in the once daily and 18 hours in the twice daily setting in all $\mathrm{BC}$ and SF positive

Table 5: Additional microbiological samples: Pathogens identified by culture from patients with positive SF and negative BC result.

\begin{tabular}{lc}
\hline Species & Organ Site \\
\hline Enterococcus faecium & Wound swab \\
Enterococcus faecium & Gall fluid aspirate \\
Enterococcus faecium & Ascites \\
Enterococcus faecium & Tracheal aspirate \\
Escherichia coli & Urine culture \\
Streptococcus species & Wound swab \\
Candida albicans & Bronchial lavage, Skin swab groin \\
Candida krusei & Bronchial lavage \\
Aspergillus fumigates & Bronchial lavage \\
\hline
\end{tabular}


Table 6: Negative SF and positive blood culture: Isolated Pathogens per Patient with negative SF and positive blood culture result

\begin{tabular}{ll}
\hline Pathogen & Note \\
\hline Candida albicans & BC positive after 5 days \\
Streptococcus pneumonia & Pathogen identified when looking retrospectively at Lightcycler ${ }^{\circledR}$ data \\
Enterococcus faecalis, Coagulase-negative staphylococci & Unknown \\
Coagulase-negative staphylococci & Suspected contamination \\
Coagulase-negative staphylococci & Suspected contamination \\
Candida albicans & Not enough blood for SF $(750 \mu$ instead of 3 ml) \\
Enterococcus faecalis, Coagulase-negative staphylococci & Unknown \\
Listeria monocytogenes & Not included in SF portfolio, Ampicillin added \\
E. cloacae & E. cloacae found, E. faecium missed \\
\hline
\end{tabular}

samples. The SF median time in the 3 samples that resulted in treatment adjustments was 21.5 hours for both scenarios (once and twice daily: 7; 21.5; 22 hours) compared to 29 hours median time for BC $(29 ; 8 ; 43$ hours $)$ for these individual cases.

Compared to the $\mathrm{BC}$ results of those samples this yields a time saving of a median of 21 hours.

In samples with $\mathrm{BC}$ negative and SF positive results a treatment adjustment was not deemed necessary in 8 of 13 samples (Table 7, Table 8). In three cases the additional use of antifungal treatment was recommended. Two other patients had not been treated for Enterococcus faecium and vancomycin was recommended as an additional drug.

Taken together, based on our proposed virtual time frame in which SF results would have become available, in 8 of 27 samples an adjustment of therapy would be triggered by the SF results. Three of those would have been made earlier while 5 would have been missed by conventional BC. Thus the use of the SF-test had clinical consequences in $8 \%$ (8 of 101) of all analysed samples.

As treatment recommendations were made post-hoc based on the clinical data available at the time of the diag- nostic results, we also looked at the actual clinical courses. In all but one sample the treating clinicians had decided in accordance with our post-hoc recommendations.

\section{Discussion}

In 39/101 samples from patients with suspected sepsis pathogens were identified with either the use of BCs or a PCR-based test for the identification of bacterial and fungal pathogens in whole blood (SF-test).

Concordance for positive and negative results between $\mathrm{BC}$ and SF $(77 \%)$ was comparable to other studies $[9,10]$.

With the $\mathrm{BC}$ results only, we identified positive results in $21 \%$ of all samples in comparison to $27.4 \%$ with the SFtest. With SF more fungal pathogens and more Enterococcus faecium were identified compared to BC. In contrast, fewer CNS specimens were identified by SF compared to conventional blood cultures.

One important question is if these pathogens additionally detected by either SF or BC are clinically relevant or if there are merely "innocent bystanders", i.e. the important discrimination between contamination, colonisation or true infection. In our patient cohort most pathogens detected only by SF were also present in other specimens

Table 7: Positive blood culture and SeptiFast ${ }^{\circledR}$ : Isolated pathogens per patient with positive blood culture and positive SF result

\begin{tabular}{ll}
\hline Identified pathogen & Therapeutical relevance \\
\hline Escherichia coli & No change: patient deceased before results became available, empirical therapy sufficient \\
Coagulase negative staphylococci & Modification necessary: Vancomycin added \\
Serratia marcescens & No change, empirical therapy sufficient \\
Staphylococcus aureus & No change, BC results leading to change were available before SF \\
Serratia marcescens & No change, empirical therapy started after sample collection sufficient \\
Enterococcus faecium & Modification necessary: Vancomycin added \\
Klebsiella pneumoniae & No change, empirical therapy sufficient \\
Candida tropicalis & No change, empirical therapy started after sample collection sufficient \\
Staphylococcus aureus & No change, empirical therapy sufficient \\
Proteus mirabilis & No change, empirical therapy sufficient \\
Enterococcus faecalis & No change, empirical therapy sufficient \\
Candida albicans & Modification necessary: Fluconazole added \\
Staphylococcus aureus & No change, empirical therapy sufficient \\
Escherichia coli & No change: patient deceased before results became available, empirical therapy sufficient
\end{tabular}


Table 8: Positive SeptiFast ${ }^{\circledR}$ and negative blood culture: Isolated Pathogens per Patient with positive SF and negative blood culture result

\begin{tabular}{ll}
\hline Pathogen & Therapeutical relevance \\
\hline Coagulase negative Staphylococci & No change, empirical therapy sufficient and probable contamination \\
Enterococcus faecium & No change, empirical therapy sufficient \\
Enterococcus faecium & Modification necessary: Vancomycin added \\
Enterococcus faecium & No change, empirical therapy sufficient \\
Enterococcus faecium, Klebsiella pneumoniae, Enterobacter cloacae/aerogenes & No change, empirical therapy sufficient \\
Escherichia coli & $\begin{array}{l}\text { No change: patient deceased before results became available, empirical } \\
\text { therapy sufficient }\end{array}$ \\
Candida krusei & No change, empirical therapy sufficient \\
Streptococcus species & No change, empirical therapy sufficient \\
Enterococcus faecium & Modification necessary: Vancomycin added \\
Staphylococcus aureus & No change, empirical therapy sufficient \\
Enterococcus faecium, Candida glabrata & Modification necessary: Voriconazole added \\
Aspergillus fumigatus & Modification necessary: Voriconazole added. Growth of colonies from \\
bandida albicans & Moncho-alveolar-lavage Aspergillus-Ag elevated. \\
\end{tabular}

of the same patient suggesting a clinical relevance. These results are in concordance with other studies where 12 of 14 respectively 31 of 42 pathogens additionally detected by PCR were present in other samples of the same patient $[9,10]$.

CNS were rarely detected by the SF-test in our collective, as the SF-test tries to omit positive results due to contamination. This is in accordance with one other study, presenting 102 patients without signs of infection with $19.6 \%$ positive BC and no CNS by SF [7]. In our study in all patients with CNS identified by BC the antibiotic treatment was not adjusted, alluding to the considered insignificance by the treating clinicians. Whether at least one of them was clinically relevant could not be judged retrospectively.

Our study showed that the use of SF in addition to BC led to the identification of more pathogens. If this was influenced by concomitant antibiotic therapy could not be addressed in our study, as $82 \%$ of the patients were already on treatment at specimen collection.

Our assumed twice daily analysis for the SF-test would have led to a median time to final results of 18 hours. Compared to usual turnaround times for $\mathrm{BC}$ results, this yields a clear time advantage for the SF-test. Immediate processing of specimens could further shorten the time to

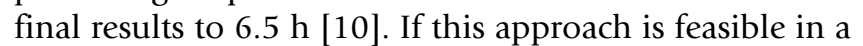
routine hospital setting has yet to be examined.

Additional pathogens were identified in 5 cases and in 3 samples the rapid SF-test would have led to earlier adjustment of antibiotic therapy. In total the use of the test would have resulted in therapeutic consequences in 8 $(8 \%)$ patients.
On the other side, 9 pathogens were not detected by SF. One of them is not included in the PCR portfolio, thus no conclusions can be drawn regarding sensitivity. Alarming is the failure of detection of S. pneumoniae, even if this could be attributed to a software problem that was solved in newer software versions. With regard to the missed polymicrobial infections it is unclear why these were not detected by SF. A possible explanation might be the competitive growth in vivo that does not allow both pathogens to reach a level resulting in a positive SF test.

All detection failures and the necessity of antibiotic resistance testing underline the importance of using the SF test additionally to standard BC.

If therapeutic adjustments initiated by the SF-test have an impact on the survival of patients with sepsis could not be determined in this study. Studies indicate that patients do not have a benefit from changes in antibiotic therapy if the initial empiric therapy did not cover the causative pathogen [4]. As those studies are based on the results obtained with current culture systems an average delay of 1-2 days has to be assumed [6]. The effect of shortening this time interval with the use of a PCR test has yet to be examined [11].

Invasive fungal infections have an especially high mortality $[4,12,13]$. Studies have demonstrated that adverse patient outcomes are related to late or inadequate antibiotic treatment. As the SF-test was superior in detecting fungal pathogens and delivers results more rapidly, the use of SF may improve patient outcomes.

The cost benefit of the SF may differ in different clinical situations or patient populations. Special equipment and specially trained personnel are necessary to perform the 
test. The cost of individual tests will be influenced by the intended turnaround time as well as by the availability outside normal working hours. Cost and cost-effectiveness analyses will have to be done for different scenarios.

Our study had several limitations. Only $80 \%$ of the patients presented with two or more SIRS criteria at the time of the specimen collections. But as the rate of immunosuppressed patients was high, a high index of suspicion was present in the remaining 20\%. Additionally, it was a non-randomized study, where the decision to use the additional test was solely taken by the treating clinician. Thus a selection bias has to be assumed that may influence the rate and types of pathogens found in our samples. Further, it is a single centre study with a small study size, thus possibly limiting the generalisability of the results. Nevertheless the design of our study may mirror clinical reality more exact than randomized controlled trials. The patients' characteristics in our study are well comparable to those of patients from sepsis studies or cohorts, including one at our institution [14].

\section{Conclusion}

Our study shows that the use of a rapid molecular diagnostic test for the identification of bacterial and fungal pathogens may lead to a higher rate of early adequate antibiotic therapy in approximately $8 \%$ of patients with suspected sepsis. Due to the small sample size and the design of our study cost effectiveness analyses were not feasible. They are warranted in further studies.

\section{Competing interests}

The authors declare that they have no competing interests.

\section{Authors' contributions}

CD participated in the design and coordination of the study, the clinical data acquisition and drafted the manuscript.

BE participated in the design of the study and helped draft the manuscript.

SS participated in the clinical data acquisition and helped draft the manuscript.

HJL participated in the design of the study.

UR participated in the design of the study and carried out the PCR.

SB participated in the coordination of the study, performed the statistical analysis and helped draft the manuscript.

All authors read and approved the final manuscript.

\section{References}

I. Nobre V, Sarasin FP, Pugin J: Prompt antibiotic administration and goal-directed hemodynamic support in patients with severe sepsis and septic shock. Curr Opin Crit Care 2007, I3(5):586-59I.

2. Garnacho-Montero J, Garcia-Garmendia JL, Barrero-Almodovar A, Jimenez-Jimenez FJ, Perez-Paredes C, Ortiz-Leyba C: Impact of adequate empirical antibiotic therapy on the outcome of patients admitted to the intensive care unit with sepsis. Crit Care Med 2003, 3 I ( I 2):2742-275I.

3. Garnacho-Montero J, Ortiz-Leyba C, Herrera-Melero I, Aldabo-Pallas T, Cayuela-Dominguez A, Marquez-Vacaro JA, Carbajal-Guerrero J, Garcia-Garmendia JL: Mortality and morbidity attributable to inadequate empirical antimicrobial therapy in patients admitted to the ICU with sepsis: a matched cohort study. J Antimicrob Chemother 2008, 6 I (2):436-44I.

4. Ibrahim EH, Sherman G, Ward S, Fraser VJ, Kollef $\mathrm{MH}$ : The influence of inadequate antimicrobial treatment of bloodstream infections on patient outcomes in the ICU setting. Chest 2000 I I 8(I): |46-155.

5. Leibovici L, Shraga I, Drucker M, Konigsberger H, Samra Z, Pitlik SD: The benefit of appropriate empirical antibiotic treatment in patients with bloodstream infection. J Intern Med 1998, 244(5):379-386.

6. Jorgensen JH, Mirrett S, McDonald LC, Murray PR, Weinstein MP, Fune J, Trippy CW, Masterson M, Reller LB: Controlled clinical laboratory comparison of BACTEC plus aerobic/F resin medium with BacT/Alert aerobic FAN medium for detection of bacteremia and fungemia. J Clin Microbiol 1997, 35(I):53-58.

7. Lehmann LE, Hunfeld KP, Emrich T, Haberhausen G, Wissing $H$, Hoeft A, Stuber F: A multiplex real-time PCR assay for rapid detection and differentiation of $\mathbf{2 5}$ bacterial and fungal pathogens from whole blood samples. Med Microbiol Immunol 2008, 197(3):313-324.

8. LightCycler SeptiFast Test. Package Insert. Roche Diagnostics $\mathrm{GmbH} ; 2006$.

9. Mancini N, Clerici D, Diotti R, Perotti M, Ghidoli N, De Marco D, Pizzorno B, Emrich T, Burioni R, Ciceri F, et al:: Molecular diagnosis of sepsis in neutropenic patients with haematological malignancies. J Med Microbiol 2008, 57(Pt 5):60I-604.

10. Louie RF, Tang Z, Albertson TE, Cohen S, Tran NK, Kost GJ: Multiplex polymerase chain reaction detection enhancement of bacteremia and fungemia. Crit Care Med 2008, 36(5): | 487-| 492.

II. Kumar A, Roberts D, Wood KE, Light B, Parrillo JE, Sharma S, Suppes $R$, Feinstein D, Zanotti S, Taiberg L, et al:: Duration of hypotension before initiation of effective antimicrobial therapy is the critical determinant of survival in human septic shock. Crit Care Med 2006, 34(6): I589-I596.

12. Pfaller MA, Jones RN, Doern GV, Sader HS, Hollis RJ, Messer SA: International surveillance of bloodstream infections due to Candida species: frequency of occurrence and antifungal susceptibilities of isolates collected in 1997 in the United States, Canada, and South America for the SENTRY Program. The SENTRY Participant Group. J Clin Microbiol 1998 , 36(7): | $886-1889$.

13. Wisplinghoff H, Bischoff T, Tallent SM, Seifert H, Wenzel RP, Edmond MB: Nosocomial bloodstream infections in US hospitals: analysis of 24,179 cases from a prospective nationwide surveillance study. Clin Infect Dis 2004, 39(3):309-3I7.

14. Audebert FX, Hanses F, Schneidewind A, Ehrenstein B, Blaas S, Salzberger B, Scholmerich J, Frohlich D, Straub RH, Gluck T: [Epidemiology of severe sepsis at a German university hospital]. Med Klin (Munich) 2007, I02(3): 195-202.

\section{Pre-publication history}

The pre-publication history for this paper can be accessed here:

http://www.biomedcentral.com/1471-2334/9/126/pre pub 